\title{
INCLUSIÓN DE LA EDUCACIÓN ARTÍSTICA EN EL CURRÍCULO DE FORMACIÓN PROFESIONAL
}

\author{
INCLUSION OF ART EDUCATION CURRICULUM IN PROFESSIONAL TRAINING
}

\author{
María Marta Gama Castro*, Freddy León Reyes** y Carlos Augusto Bahamón Cardona***
}

\begin{abstract}
RESUMEN
Este artículo surge de la investigación que se está haciendo con jóvenes universitarios de diferentes disciplinas del saber y la interpretación que dan de las formas y los colores partiendo de procesos experimentales de motion graphics, donde cada uno de ellos hace una representación abstracta de los colores y las letras, y su interpretación con las formas. Estos jóvenes fueron radicalmente formados bajo procesos tradicionales en educación artística, donde la opción de interpretar los colores era invalida. Sólo se aceptaba la interpretación de la realidad. Se busca con el proyecto reevaluar el sistema educativo que da parte sólo de unas áreas específicas del saber pero deja de lado otras áreas que bien pueden y deben ayudar a complementar la formación profesional de los jóvenes de diversas profesiones en Colombia.
\end{abstract}

Palabras clave: Arte, disciplinas, educación, estética, profesionales.

\begin{abstract}
This article stems from research that is being done with university students from different disciplines of knowledge and the interpretation given to the shapes and colors from experimental motion graphics processes, where each makes an abstract representation of the colors and literature, and its interpretation with forms. These youths were trained under traditional processes radically in art education, where the option was invalid interpret the colors. Only the interpretation of reality is accepted. Project seeks to reassess the education system giving only part of a specific knowledge areas but neglects other areas that they can and should help supplement the training of young people from various professions in Colombia.
\end{abstract}

Keywords: Art, disciplines, education, aesthetics, professional.

Fecha de recepción: Junio 18 de 2014 / Fecha de aceptación: Octubre 09 de 2014

Tipología: Artículo Corto

Para citar el artículo: Gama, C, M., León, R, F., \& Bahamón, C, C. (2014) Inclusión de la educación artística en el currículo de formación profesional. Praxis, Vol. 10, 176 - 188

*Magister en Comunicación Educación Universidad Militar Nueva Granada, Colombia. E-mail: maria.gama@unimilitar.edu.co.

**Magister en Educación Universidad Militar Nueva Granada, Colombia.E-mail: freddy.leon@unimilitar.edu.co.

***Magister en Diseño gráfico y Creatividad estratégica Universidad Militar Nueva Granada, Colombia. E-mail: carlos.bahamon@unimilitar.edu.co. 


\section{INTRODUCCIÓN}

$\mathrm{D}$ esde la escuela se enseña al niño a identificar primero las formas y partiendo de ese principio se le enseñan los colores básicos y fundamentales que debe acompañar a la forma, ejemplo: el caballo es café o negro y de esos colores no puede ni debe salirse. El caballo no puede ser azul.

Tradicionalmente se enseña en el aula principios básicos de formas y colores, sin opciones de cambio, se debe copiar fielmente de acuerdo con la realidad. En muchas áreas del saber, son también muchos los profesionales que básicamente desconocen la estética de interpretar de manera visual sus proyectos. Hoy en día se acude a diferentes sitios a ver ponencias que acompañan con presentaciones rutinarias, frías y simples y con una visión fuera de lo estético.

Esta investigación abrió espacios de participación de estudiantes de diferentes facultades de la Universidad Militar Nueva Granada, que fueran particularmente en su mayoría estudiantes que no tuviera ningún acercamiento con el arte. Esto permitió que se pudieran evidenciar principios básicos de mal uso de la composición, en primera instancia, llevando a los estudiantes casi profesionales a tener una mala concepción de lo bello. No se puede negar que para cualquier persona que poco sepa de estética del arte sea algo muy especial y llame mucho su atención el hecho de observar, mirar, y deleitarse con una visón que transmita su propio mensaje, sin recurrir al abuso del texto.

La transformación de la enseñanza de la educación artística en diversas disciplinas se hace necesaria. Lo que usualmente países como Estados Unidos hace en el aula de clase. Mediero, Fresno \& Garcia. (2003) dice:

En Estados Unidos se desarrolla la Educación Artística como Disciplina, ella se dirige a cuatro objetivos principales: ayudar a los estudiantes a desarrollar la imaginación y adquirir las aptitudes necesarias para una ejecución artística de calidad; aprender a observar las cualidades del arte que ven y a hablar de ellas; comprender el contexto histórico y cultural en el que se crea el arte; y abordar cuestiones relacionadas con la teoría estética a través de las cuales puedan tener su propio punto de vista sobre el significado del arte. (p.15).

En Colombia se enseña, lo que conocemos como educación artística de una manera muy rígida. El niño se acostumbra a lo que se diría en computación al copy paste. Es decir, lo que se ve, se debe copiar. El niño a temprana edad comienza a descubrir los colores por relación, es decir: el limón es verde, la manzana roja, el cielo es azul. Igual pasa con las formas, la relación del círculo con el sol, la luna, la tierra, etc. Pero y ¿la habilidad para la creación? Si un niño se sale de esos convencionalismos usualmente es un niño con problemas. Se busca es llevar al estudiante a idealizar las formas y los colores, se busca escudriñar en cada estudiante y buscar en el su pensamiento crítico y artístico las posibles descripciones personales de lo que considera “bello”. Es como dice Kandinsky (1917):

En el arte no existe la forma totalmente concreta. Es imposible reproducir exactamente una forma material: quiéralo o no, el artista depende de sus ojos y de sus manos, que en este caso son más artistas que su alma, que no persigue más que un objetivo fotográfico. El artista consciente, sin embargo, no se contenta con registrar el objeto material sino que intenta darle una expresión, lo que antiguamente se llamaba idealizar, más tarde estilizar y mañana se llamará de cualquier otra manera. (p.50).

Ya en secundaria, el estudiante forja su experiencia hacia los conocimientos que se "deben" aprender en otras asignaturas que para el gobierno se ha convertido en lo básico del aprendizaje de los jóvenes como por ejemplo lo son las matemáticas que desarrollan pensamientos racionales y lógicos sin ningún tipo de variación posible, la capacidad de resolver problemas puede presentar una, dos o tres variantes pero el resultado debe ser el mismo. Las ciencias naturales y las sociales 
preparan al estudiante para que puedan resolver situaciones a partir problemas que involucren a la comunidad, con la intención de estimular la crítica y la investigación.

Se espera que en los seis meses de estudio (un semestre académico) que se lleva de esta investigación, los resultados sean claros como el simple hecho de potencializar en cualquier estudiante un tipo de apreciación y estética hacia las formas y los colores desde la visión de un profesional de cualquier disciplina en proceso. No se entiende cómo en todas las carreras se abordan asignaturas con contenido profundo de lo que se estudió en el colegio, pero justamente es la educación artística la que menos se aplica en ésta otras disciplinas, llegando infortunadamente al desparpajo visual del más mínimo e insignificante proyecto, hasta el más complejo e importante.

El desarrollo de la investigación, aplica el concepto del motion graphics, con el fin de desarrollar proyectos con propuestas visuales amenas, donde la tipografía, la animación, el color y la composición visual sean el campo de acción del desarrollo de sus nuevas presentaciones de trabajos.

El profesor Vásquez (2013), coordinador de la Especialización en Educación Artística Integral de la UN, afirmó:

Se nota que no estamos hablando de una educación para la formación de artistas en sentido profesional sino del derecho que todo ciudadano tiene a una sensibilidad, a una manera de observar el mundo y un enriquecimiento de su vida propia. Paradójicamente, venimos de la práctica artística y es desde allí que pensamos lo social.

\section{METODOLOGÍA}

La metodología de investigación aplicada al proyecto es la Investigación-Acción. Sobre esto Pérez (1994), afirma que:

La Investigación-Acción que se adscribe al paradigma crítico (investigación en educación), el cual postula la necesidad de investigar con la finalidad de superar las contradicciones de la acción social y de las instituciones sociales. Este enfoque metodológico se caracteriza por la sistematización y mejora de la realidad concreta, es flexible, democrático, abierto y propicia acceder a los fenómenos educativos tal y como suceden en la realidad, empleando variedad de métodos que contribuyen con las decisiones. (p. 70).

De acuerdo con Carr \& Kemmis; (1988), defensores de este movimiento, "la educación no es una actividad teórica, los problemas que debe atender son prácticos, lo que significa que no quedan resueltos con un nuevo saber, sino con la adopción de una línea de acción” (p.45).

Durante el desarrollo de la investigación, se plantea la problemática que vive un profesional (que no tiene conocimiento en arte) y qué tipo de componente es el que lo separa de tener una visión estética sobre la apreciación y el valor visual sobre sus trabajos. Enfrentándose a un desafío muy grande, ya que cualquier carrera profesional en Colombia que no tenga relación con las artes y el diseño se ven enfrentados a un serio problema de estética visual, que afecta a sus egresados y que además redunda en la formación profesional de los jóvenes que se están formando en los diferentes programas técnicos, tecnológicos y profesionales. Algunos con escepticismo, pero sin negar sus grandes habilidades y destrezas en su disciplina, creen que este sería el complemento perfecto de aplicación de conceptos a sus proyectos y dejar la monotonía de lo tradicional y frio.

Esta investigación, abre espacios de participación a los estudiantes, llevándolos por procesos de cultura visual que les amplía el campo y el gusto por los medios visuales y audiovisuales. Se hace el diagnostico con estudiantes de Derecho, Administración de Empresas, Ingeniería Civil y Medicina, hasta conseguir hacer el estudio con sólo un estudiante de cada programa. Ese diagnóstico arroja la problemática del conocimiento y conceptos básicos de diseño, teoría del color, composición y diagramación. Posteriormente se 
elabora un cronograma y se comienza a abordar el proyecto con instrumentos de aplicación tales como: diarios de campo, grupos de discusión, fichas de estudio por cada estudiante, trabajos prácticos de participación.

En los diarios de campo se observa la actitud receptiva y crítica sobre sus propios trabajos, se hace un seguimiento hacia la experiencia de enfrentarse por primera vez a diversos movimientos artísticos, ya no observando lo "decorativo" de una obra sino su implicación sobre el espacio en el que se proyecta. Obras de diferentes autores reflejaron en los estudiantes una emoción que contrastaba con lo que para ellos era bello o no. Esto permitió ir definiendo un estilo particular sobre sus proyectos.

Durante los grupos de discusión se encontró que los estudiantes hallan muchas falencias en el sistema educativo desde el inicio de su formación elemental, es decir, que de niños no se le da importancia a la educación artística, convirtiéndose en una materia "de relleno" para muchos. Con el agravante que aunque hay un compromiso por el "arte bello" se desconoce su aplicación y pasa a convertirse en un enemigo público de aquel que por simple desconocimiento convierte lo bello en una estética totalmente opuesta a su principio y fin básico: gusto al observar.

El sistema educativo en Colombia y el MEN (2007), sobre los lineamientos curriculares y los estándares de competencia básicos, plantean:

(...) diversidad de escenarios sobre las construcciones conceptuales, proceso de pensamiento y la dinámica de las áreas del conocimiento, y sobre las áreas del conocimiento dice: Cualquiera sea la actividad artística (música, teatro, pintura, danza, culinaria, artesanía, etc.), los lineamientos curriculares plantean el desarrollo de cuatro ejes de formación: el pensamiento contemplativo, la reflexión conceptual, la simbolización y el juicio crítico.

Ante esto los estudiantes reflexionan y aseguran que no es así.
El otro instrumento ha sido las fichas de estudio por cada estudiante, que develaron cómo los estudiantes de las carreras escogidas, carecen de muchos principios estéticos, inclusive dejando ver que estos temas son efímeros y sin importancia. Mientras se logre comunicar e informar lo demás sobra. Lo importante según ellos es que "sea lo que sea, lo que se va a informar, lo importante es que quede claro”, el valor estético agregado no tiene sentido si el mensaje llega al receptor y cumple su objetivo.

Pero se pone de manifiesto, cómo en algunos casos se recurre por lo menos a las gráficas, para hacer entender a la gente la información que se va a dar.

En los trabajos prácticos de participación se explora la parte artística de cada participante, es decir, primero se contextualiza; segundo, se hace mucho trabajo de visualización y comunicación por medio de imágenes, el texto debe ser parte de la imagen, es decir, no es aleatorio, es parte esencial entre la imagen y él, y tercero se desarrollan trabajos donde la teoría del color sea aplicativa a todo principio, al igual que los pocos textos que la acompañan y además la composición, cómo se arma, cómo se coloca cada cosa para que haya un equilibrio y una armonía.

Las experiencias contadas desde la perspectiva de los participantes se usan para construir un panorama detallado de los factores que han influido en el fenómeno estudiado. Se van desarrollando gradualmente durante un periodo de tiempo porque dependen de un alto grado de cooperación y confianza entre el investigador y los participantes.

Partiendo de estas experiencias contadas se procede a hacer una experimentación pedagógica, que parte de esas mismas experiencias contadas y que avalan el proceso. Ancizar \& Quintero, (2010) dicen:

La experimentación conserva su carácter de instrumento de contrastación de teorías para construir conocimiento válido y aceptable por las comunidades científicas y académicas. La experimentación 
facilita la reconceptualización y la escritura de lo que se está haciendo, de la experiencia acumulada y reflexionada. La escritura es una práctica intelectual del maestro. En el campo de la experimentación, los docentes cumplen un ciclo que va desde observar, ensayar, analizar, interpretar, comprobar hipótesis y generar teorías. (p.6)

\section{El arte se experimenta}

Durante esta parte de la investigación se hizo un análisis sobre lenguaje visual, con definiciones propias y un sentido crítico sobre lo que se investiga y cómo se investiga en educación. Se define con exactitud el método y la técnica a desarrollar en sus proyectos. Cada proceso conlleva a ser muy objetivos con el propósito de darle fuerza a sus propias líneas temáticas y tipos de estética (Hernández, 2000).

Ellos, en este primer acercamiento, experimentaron la necesidad de desarrollar esa habilidad de apreciación visual, que se les permitió desbordar simplemente por medio de imágenes y tipografía en movimiento el análisis de ellas desde su mínima experiencia con el arte.

Es claro que la escuela jerarquiza entre arte y ciencia, la ciencia es conocimiento y razón: el arte es subjetivo, emocional y pasional, esto inclusive ha dado que en arte el tema de la investigación sea algo efímero.

\section{La Educación Artística}

En este paso se aplica el siguiente instrumento, los grupos de discusión. En este punto del proceso se alcanzan logros más allá de los esperados, pues cada uno de ellos basados en textos de MEN y el Ministerio de Cultura (2013), evidencian que a pesar del propósito de estos entes por hacer de la educación artística un proceso de cambio generador de conocimiento y una necesidad de todo ciudadano, en algún punto de la formación académica esto se ha quedado en palabras. No es verdad, lo que ahi dice se evapora, es lo que dice Karol (estudiante de $7^{\circ}$. Semestre de Derecho). Para ellos esto no es más que una utopía.
En Colombia la formación artística y la práctica de la misma se establecen como un derecho de todo ciudadano, se supone que crea participación, subjetividad y desarrollo cultural. La Unesco (2002) afirma:

(...) las personas no solamente disfrutan de la experiencia sensorial que les brinda el arte, sino que se convierten en actores activos del mismo. Es decir, el arte como un derecho de todos los ciudadanos. La educación artística como diálogo entre los lenguajes y medios de las artes contribuyen a: Involucrar a los ciudadanos en la construcción de conocimiento. Desarrollar la capacidad de observación y transformación de la realidad desde distintas miradas. Formar ciudadanos con capacidad de cuestionar, proponer, emprender crear e intervenir su entorno social. Reconocer que el proceso de formación artística no tiene límites y se desarrolla a lo largo de la vida. (p. 67)

De acuerdo con el perfil de cada una de sus carreras, ninguna ofrece esta formación artística y mucho menos en sus colegios se vio la clase de arte con la seriedad y la connotación que se supone debe reflejarse en la formación de un estudiante en cualquier nivel.

En la discusión se destaca el hecho de que el que nace artista casi en su formación básica se forma empíricamente, no así pasa con el matemático o físico, tampoco con el que se apasiona por las letras o por las ciencias sociales.

El niño que llega a la escuela con un gran valor hacia lo estético, es él, es su gusto, pero no es por lo que se enorgullece el profesor. Crece con esa simpatía hacia la estética del arte y pueden suceder dos cosas: una, que siga la línea artística haciendo de ella su proyecto de vida; o dos, que en el proceso de formación el sistema educativo modifique esa intensión y se convierta en un profesional más de cualquier otra disciplina que lo aleja de lo que realmente fue su ideal desde niño. La mayoría de los jóvenes estudiados en este proyecto manifestaron que siempre les gustó 
el contacto con los materiales, los colores, las temperas o vinilos, así fuera la clase de hacer fielmente lo que se observa y limitando la creación y la interpretación. Fue de esas materias que se querían con especial afecto, lástima... no entiendo qué pasó, a mí me gustaba mucho esa clase, dice Brian (estudiante de $9^{\circ}$ semestre de Ingeniería Civil).

La Organización de las Naciones Unidas para la Educación, en su Hoja de Ruta de Seúl, suscribe convenios dónde se compromete a garantizar la educación artística durante la vida, pero ese compromiso no se cumple, por lo menos en lo que con la educación en Colombia se refiere. Es claro que el estudiante culmina su bachillerato con un objetivo claro sobre la carrera a seguir, y en muchos casos se van con carreras que no tienen ningún enfoque artístico porque justamente en eso presentan mucha debilidad.

\section{El sentido global de la educación artística}

Un paso a dar sería evaluar cómo se ha construido el currículo de formación de educación artística en otros países y cómo se enseña, qué se enseña y por qué se enseña. España y México, sólo para citar un poco, tienen en sus profesores la tendencia de no partir de cero, es decir, ellos tienen un conocimiento que se formula como marco teórico y práctico desde un nivel histórico, epistemológico, sociológico y ético, entre otros, con el fin de formar ciudadanos capaces de percibir y analizar con criterio una obra plástica con el objetivo de generar un sentido crítico, objetivo y conceptual del estudiantado. Y aún van más allá; buscan definir las tendencias económicas y políticas de una nación con el fin de buscar esos momentos históricos que han contribuido a definir resultados artísticos. Así como la contextualización de la formación artística de hombres con principios pedagógico-sociales que perduren en su conocimiento cultural. Todo esto deriva de una disciplina rigurosa y de pedagogías con perspectivas cambiantes que pone de manifiesto la importancia de enseñar la educación artística desde la formación inicial del niño.

En países como Estados Unidos, la investigación en este sentido ha vinculado en sus universidades profesores de diferentes disciplinas y niveles educativos con el fin de ampliar y sistematizar los problemas que surgen alrededor de la formación artística. Pero desafortunadamente la falta de discusión, conceptualización y cooperación de profesores de estas diferentes disciplinas han llevado a un reduccionismo de modelos de investigación en educación artística. La educación artística en Argentina, es clara cuando dice que no busca formar artistas desde su enseñanza básica primaria, su finalidad es: "la Educación Artística como área privilegiada para el desarrollo de capacidades vinculadas a la interpretación crítica de la realidad socio - histórica y a la producción cultural identitaria en el contexto de la contemporaneidad". (Ministerio de educación de la Nación. Buenos Aires. 2008) Es de notar que en este sentido, es muy importante generar modelos que expliquen la teoría artística y estética, y que se imparta a docentes de todas las disciplinas con enfoques ilimitados con el fin de ampliar la formación sobre educación artística.

\section{Lenguaje visual}

Un punto fundamental que se ve necesario estudiar es el lenguaje visual, cómo se comunica a través de la imagen y aún más de qué manera se deben usar las imágenes para que se adapten a lo que se va a comunicar, informar o simplemente agradar con ella. Por esto se comienza a elaborar una ficha de aplicación a cada estudiante, que partiendo de la información que se da sobre comunicación visual empiecen a plantear desde su propio saber aplicaciones con imágenes y tipografía que sugieran los contenidos.

Si se habla de comunicación visual no se puede limitar a un solo tema ya que como comunicación es precisamente esencial informar a través de ella. Como todo principio de comunicación obviamente requiere de un emisor, un transmisor, un receptor y un canal, que es el que soporta la vía o el medio utilizado.

Igualmente la imagen se debe ocupar de cumplir varias funciones dentro de esa comunicación: 1)

Expresiva o emotiva, que busca sensibilizar y generar emociones fuertes en quien observa la 
imagen. 2) Cognitiva, apelativa o exhortativa, hace relación a la convicción, llevar al convencimiento, muy utilizada en publicidad. 3) Poética o estética, es tal vez de las más bellas funciones de la imagen, pues tiene el poder de deleitar y seducir con su belleza "poética", es lo que la mayoría de artistas hacen en sus obras, buscar una belleza totalmente estética que se contemplativa y agradable a quien la observa. 4) Fática, debe llamar la atención de manera abrupta, muy utilizada también en publicidad. Y aunque a diferencia de la cognitiva, no busca convencer pero sí tener una gran recordación en la memoria. 5) Metalingüística, cumple una función bastante exhortativa si se puede manejar de esta forma, es ese tipo de imagen que no utiliza el texto para comunicar, pero informa de una sola forma, un gran ejemplo de ellos serían las señales de tránsito. 6) Descriptiva, las ilustraciones científicas son un buen ejemplo de ello. Se debe ser muy exacto y preciso en el tipo de información que se da, no debe contener supuestos. De todas las funciones esta requiere de una responsable investigación.

Muchos se preguntaron sobre la marca, el signo y el símbolo, todo esto se relaciona un poco con la manifestación de las imágenes por medio de la expresión del cuerpo. Se puede hacer un profundo análisis de lo que se comunica a través del cuerpo; las manos, los ojos, la cara, la posición del cuerpo, etc. Muchos admiran la cadencia en la danza que tiene los raizales y la sensualidad que con esos movimientos ellos transmiten, pero todo esto tiene un origen. Cuando los negros fueron traídos a América como esclavos y sometidos a largas caminatas y a hacer su trabajo en silencio, sin hablar entre ellos, aprendieron entonces a utilizar sus propios cuerpos para llegar a una comunicación, con movimientos identificaron un lenguaje que sólo ellos descifraban. Movimientos que generaron entre ellos una identidad, y que hasta hoy en día saben manejar y que los identifica solo a ellos. Manejaron símbolos y signos de comunicación corporal, que los acercaron y que hasta hoy en día hace parte de su propia identidad.

Pero volviendo al sentido de la marca, el signo y el símbolo, se puede mencionar que este tipo de imagen ha modificado el lenguaje comunicacional de la misma. La marca es invasiva, llega, se expande y se queda, lo son las grandes marcas mundiales, se puede identificar la marca como una posesión, como lo que identifica a algo que tiene dueño; la firma es una marca. El signo a diferencia de la marca identifica una indicación, una orden o una prohibición, las señales de tránsito, por ejemplo, se han convertido en signos que no necesitan especificación alguna, simplemente con verlo se sabe a qué corresponde.

\section{Motion Graphics}

Recurrir al motion graphics fue la pieza que dio origen a este proyecto, ya que partiendo de esto se fue evidenciando la necesidad de aprendizaje en arte que se plantea en este artículo. Sánchez (2014), define:

El Motion Graphics hace referencia a la animación gráfica digital multimedia. Digital porque se realiza con un software y de forma no lineal. Multimedia, porque reúne en una misma producción elementos de diferente naturaleza. Gráficos vectoriales como ilustración y tipografía, gráficos mapas de bits como fotografías y montajes, recursos de video que se hacen con capturas y clips de películas y recursos de audio como efectos especiales y música.

Los videos en tiempo real se implementaron en la historia del videoarte gracias a la creación de los video jockey, que logran aplicaciones musicales con video manipulados en tiempo real. Nam June Paik, quien será el pionero del video arte fue un artista irónico y crítico, capaz de unir en sus piezas; tecnología, espiritualidad oriental y crítica con la sociedad de la información, esto como intención primaria de crear espacios exclusivamente dispuestos a un público con la capacidad genial de crear imágenes partiendo de su descripción del sonido.

El proyecto que desarrolla cada estudiante se enmarca dentro de la necesidad de volver a esos momentos instantáneos de proyección, que con el paso de los años fue una exquisita obra de 
arte en la que no sólo la imagen es la que dispone del tiempo en el espacio que se proyecta, sino la imagen que con otros elementos que la acompañan como las letras se convierte en una incitación a sentirlas por sí mismas como personajes que ejecutan acciones y gestualizan con cada movimiento que se da.

\section{La estética visual de un profesional de cualquier disciplina}

Desde el anterior ejercicio dónde se plantean las diferentes funciones de la imagen se comienzan a desarrollar los trabajos prácticos de participación (otro instrumento de aplicación), que formula la idea de construir imágenes para cada asignatura de su carrera. Con imágenes representar los contenidos de su perfil profesional.

El comienzo no es fácil para ellos, ya que no están acostumbrados a comunicar a través de imágenes. Un buen ejercicio que les ayudó a concentrar su idea de comunicación visual, fue recurrir a los periódicos impresos y digitales. Es evidente que la mayoría de veces lo que lleva a la lectura y ampliación de una noticia es lo que la imagen del artículo o nota muestra.

Este buen comienzo los lleva a indagar de qué forma puede la imagen reemplazar el texto y si ese texto se utiliza cómo simplificarlo y complementarlo con la imagen. Sobre la práctica y el conocimiento Sundín, (2003), dice:

El conocimiento se construye por medio de la práctica, y no está fuera de los propios actores. Es en el modo en que nos aproximamos a la realidad para reflexionar sobre ella donde se hallan las condiciones para acceder a un nuevo conocimiento y para mejorar la práctica educativa. (p. 99).

Ante los resultados de las propuestas de sus proyectos surge una inquietante pregunta. ¿Hay presupuesto para implementar desde la escuela la formación artística en todas las áreas? Demmer precisó que "no hay presupuesto para la educación artística, solo se quiere garantizar en medio de la precariedad" (Demmer, 2013). A pesar de los esfuerzos que teóricos hacen por implementar en la educación formal la formación artística, es muy difícil que se lleguen a esos resultados con estímulos que realmente justifiquen la modificación curricular en este sentido. Es más se ha llegado a plantear en algunos círculos que el aporte debe ser más por "amor al arte" de los profesores artistas a que haya un verdadero cambio a esto. En México se han generado recursos, más el aporte cultural de expertos. Pérez (2013), subdirector de Promoción Cultural de México, dijo:

Es una problemática a nivel de Latinoamérica. Nacemos con la creatividad, así que es importante desarrollar programas y estrategias para la gestión de cultura a través de la educación de las artes plásticas. En México se han ido estableciendo recursos desde 1998, cuando se creó el Consejo Nacional para la Cultura y las Artes se empezó a implementar mediante la educación no formal el acercamiento a las artes a través de la literatura y con el apoyo de artistas de renombre.

Es innegable entonces que el ejercicio práctico de la creatividad no se pierde, se debe cultivar y madurar, y más allá de las estrategias de profesionales y del gobierno se deduce que sí se puede hacer arte desde el principio básico del conocimiento; es decir, si se informa, se valora, se construye arte, la objetividad puede fluir para cualquier profesional. Precisamente sobre el desarrollo artístico de la primera infancia Gardner (1994), dice:

El conjunto de las formas artísticas se pueden analizar de forma fácil en función de pocas formas de conocimiento. Los niños participan en el arte como creador y como preceptor, aunque en la $1^{\mathrm{a}}$ infancia manifiestan formas de conocimiento contemplativo, pero hasta más tarde no son capaces de leer las imágenes y de crearlas con significado. (p. 241) 


\section{La transformación del currículo}

En los anteriores párrafos se citan las necesidades básicas de los niños y jóvenes que se encuentran en su proceso de formación. Pero no nos podemos alejar del tipo de personalidad que generan esas empatías por las artes. Es un hecho que el arte se puede expresar de muchas formas y quienes lo hacen, tienen una especie de afecto por el mismo. Pero iqué sucede con aquellos que no sienten aprecio ni gusto por él? ¿Cómo se puede llegar a estos jóvenes que así como a muchos las matemáticas o la biología no les gusta?

Para casos específicos no se puede generalizar, es decir, la educación en Colombia debe ser y abrir espacios más hacia la aptitud, si se conserva ese gusto desde niño es muy probable que como adultos se sirvan de esos conocimientos artísticos para aplicarlos a sus proyectos de acuerdo a la selección de su disciplina profesional. Un estudiante de Diseño Gráfico de una reconocida universidad de Bogotá tiene un problema en sus manos de quiste sinovial (muñeca con bolsa o saco lleno de agua) que lo ha llevado a presentar dificultades desde niño con el desarrollo de la motricidad, aunque asume su condición de forma traumática su creatividad no se ve limitada por esta razón, todo lo contrario sus aportes y resultados son óptimos y se convierte en un modelo para la clase.

Las cualidades y el gusto, (eso es lo que se busca si se modifican los currículos, cualidades artísticas y estéticas aplicadas al aspecto visual de sus proyectos en curso) deben ser evaluados y puestos a disposición del profesor que imparte y evalúa los resultados finales, resultados que deben ser valorados y apreciados de acuerdo a las capacidades artísticas y formativas de cada estudiante, con el fin de buscar una motivación cada vez más estimulante hacia lo que hacen.

El currículo, entonces, debería ser flexible en ese aspecto, llevando a los jóvenes en cualquiera de sus niveles de formación a la experimentación con sus aptitudes y habilidades creativas sin miedos ni rechazos, sin concepciones de conceptualización, sólo si las necesidades de la visualización de los proyectos los obligan. Hoy por hoy, el arte no solamente es la descripción subjetiva del artista. El arte plantea la necesidad de incorporar el conocimiento, el aprendizaje y herramientas a proyectos que comuniquen, eduquen y entretengan.

\section{RESULTADOS}

\section{Implicaciones del arte en el aula de clase, en la educación básica primaria}

El arte es esencial en el proceso educativo, puesto que es una actividad dinámica y unificadora y para el niño es primordialmente un lenguaje del pensamiento, en donde exprese algo más que un dibujo o una escultura; donde el niño proporcione una parte de sí mismo: cómo piensa, cómo siente y cómo ve el mundo que lo rodea.

Los profesores en la escuela necesitan como uno de los primeros objetivos que se plantean, fomentar la actitud creadora en los niños. Solamente a través de los sentidos puede tener lugar el aprendizaje, ya que el hombre se está convirtiendo en un observador pasivo de su cultura, antes que en un constructor activo de ella. Con el arte se desarrolla la competencia estético expresivo con tiempo, paciencia y trabajo sistemático, integrando conceptos y actitudes que permitan producir y comprender mensajes estéticos desde diferentes lenguajes artísticos, como un modo de posibilitar un desarrollo integral.

El arte puede ayudar a que los niños aprendan, en este periodo se desarrolla una de las más valiosas potencialidades: la creatividad, estimula la curiosidad, la invención y el descubrimiento, también el reconocimiento de formas, tamaños, volúmenes, grosores, textura; el establecimiento de relaciones espaciales; le da al niño también la oportunidad de expresar ideas, así como el interés de observar y experimentar su relación con el mundo que lo rodea, además, lo ayuda a potenciarse como integrante activo dentro de los programas educativos infantiles, el cual se debe convertir en un aliado de inmenso valor para los docentes ya que es una de las estrategias creativas dentro del aula. 
Educar es vivir y comprender simultáneamente la vida, el arte es constructor de ideas, con él se ayuda a que los niños identifiquen problemas e incluso que los propongan. Al reforzar los cimientos gracias a una libertad de análisis, síntesis y expresión los niños se convierten en los seres más ingeniosos, comunicativos e interesados.

La enseñanza del arte es vital en la educación de los estudiantes en los diferentes niveles educativos. Como parte esencial en el proceso de formación de los niños y niñas. Adquiere mayor importancia al demostrarse su acción determinante en el desarrollo de las capacidades y potencialidades que ellos poseen. Desde sus diferentes manifestaciones como son, la música, el teatro, la danza, la pintura; el arte aporta al estudiante un sin número de beneficios que son el armazón sobre el cual se desarrollan, las capacidades y competencias necesarias para su vida, que conlleva a fortalecer su formación integral y compromiso con el progreso de su nación, además posibilita el desarrollo de sus potencialidades, permitiendo que sea el propio estudiante quien vaya explorando y descubriendo sus propias habilidades. Su carácter lúdico, sumerge a los estudiantes en ese mundo del juego donde no existen reglas, ni limitaciones, invitándolo a crear y proponer sus propias reglas.

La estimulación de las capacidades cognoscitivas y creativas de los estudiantes, hacen que desarrollen la atención, percepción, memoria, retención, discriminación, movimiento, audición, vocabulario, expresión corporal; además permite una mejor socialización e interacción con su entorno.

Es muy importante que los docentes tanto de básica primaria como de básica secundaria asuman una actitud responsable y comprometida hacia la educación artística, seleccionando y ejecutando actividades artísticas que con estrategias metodológicas adecuadas, logren los objetivos que como fin último tiene el arte, es decir la expresión libre, espontánea y natural que se logra en el proceso.

Se debe recordar o reflexionar sobre las vivencias que se ha tenido en todos los procesos tanto de estudiantes como de maestros ya que si la mayor parte de la vida estuviera marcada por experiencias de aprendizaje artísticos, este mismo acto de aprender sería un premio gozoso y por lo tanto, ni siquiera sería necesaria la nota o calificación del maestro, siendo éste el instrumento verdadero y positivo para la formación de los maestros. Si el niño en su entorno familiar y educativo no despertó sus capacidades perceptivas hacia la naturaleza, la plástica, la música, etc., es probable que en su madurez, difícilmente, esté motivado a preocuparse por estos aspectos, salvo que tenga latente un gusto o apreciación especial hacia el arte.

Por ello, es tan importante abordar la educación como una armonización de las facultades humanas desde la más temprana edad. Y esto no es sin duda el "rellenar" la mente de un niño con datos o memorizaciones para ponerlo más "inteligente", o para convertirlo en un ser "pensante" antes de tiempo, cuando su desarrollo está apuntando, más bien, a establecer otros aspectos de su individualidad.

\section{Competencias de un profesional}

La educación artística se ha convertido para muchas escuelas en un valor agregado, se debe dictar porque lo exige la reglamentación, pero no hay un acercamiento a los conceptos. Normalmente quien dicta -en el caso de los niveles de primaria- es el mismo profesor que enseña matemáticas y español en el colegio. Muchos de ellos no están capacitados para asumir la asignatura con la claridad y sensibilidad que un profesional en esta área lo hace.

Infortunadamente los resultados sobre las competencias que los estudiantes deben desarrollar durante su carrera deben ser del orden: instrumental, interpersonal y sistemático, definiendo que cada una de ellas incorpora las capacidades cognitiva, metodológicas, tecnológicas, lingüísticas, capacidades individuales tales como habilidades sociales, interacción y participación social y ciudadana, y las capacidades que se relacionan con los sistemas de conocimientos y de comprensión. Es fácil observar que no se requiere de mucho esfuerzo para concluir que 
las competencias en formación artística no se exigen bajo ningún principio de proyección hacia el futuro.

Entonces qué interés tiene el profesor en capacitarse para enseñar. Desde la escuela hasta la universidad el énfasis artístico es prácticamente nulo, la concepción de valorar la estética visual no se hace presente.

Para este grupo de estudiantes queda claro que cuando se habla del sentido estético de las cosas, nos estamos refiriendo a su belleza y no como una simple circunstancia de las imágenes que se referencian.

\section{El Arte Bello}

El arte bello, afirmaría Kant, era "aquel cuya forma generaba un sentimiento de placer en el observador".

El arte, según esta concepción, es emocional, subjetivo; requiere de la habilidad y la capacidad de interpretación. Aunque para algunos el arte requiere de si se tienen o no se tienen habilidades; pero para otros permite sólo la necesidad de que el sujeto exprese su interior y que refleje en forma transparente el exterior; entender, conmover, adornar, embellecer; usa la metáfora, los conceptos de narración sobre el lenguaje visual. El arte siempre se liga con el sentimiento, esto lo experimentan cuando por medio del conocimiento del lenguaje de las imágenes, captan que el impacto sobre la imagen debe ser subjetivo y que la interpretación es abierta a toda posibilidad. Pero, aplicar ese principio sobre sus trabajos sólo se logra con una verdadera aceptación de la lógica de las formas básicas y elementales de la composición. Una buena experimentación fue estudiar la teoría del color y su significado psicológico, esto los llevó a concentrar su atención en la expresión a través de la escala cromática que se debe al lenguaje de los colores.

Un músico experimenta apreciar los sonidos por medio de los colores y algunas veces las notas las pueden sentir muy azules. Así mismo el valor del color experimenta esa comunicación entre la forma y la emoción. No se puede experimentar la representación del arte sin pensar en algo.

Este ejercicio les permite ver que ellos crecieron con la idea que el arte era "innato", que no existía la posibilidad de aprender, para algunos de ellos inclusive desde la casa, de sus propios padres escuchaban que el arte no era para ellos. Se puede decir que todos los niños nacen con esta habilidad o, por lo menos, con el gusto por el dibujo y la pintura, pero en el proceso de formación académica van perdiendo esa sensibilidad y convierten a la clase en la clase "de costura", y al arte en un estudio de formación para "vagos" y la seriedad con la que se debe tomar se rompe y genera en la mayoría ese abandono a toda práctica.

Por esta razón, conocer y actuar convierten a la práctica en objeto de investigación, formando parte de un mismo proceso exploratorio.

Alrededor de los planteamientos de sus proyectos y los resultados de los mismos, queda un aporte muy valioso a la calidad académica en cada uno de sus programas en cuanto a las competencias que los define como futuros profesionales, argumentar, plantear, desarrollar o intervenir en proyectos que incorporen elementos tecnológicos, comunicativos, pero en lo estético el vacío se presenta.

\section{La estética de lo feo}

Lo estético es deleite, es placer. Que lo feo pueda gustar parece un contrasentido.

En este punto de la investigación se observa muchas obras de arte con el fin de analizar la estética de lo bello en cada una de ellas, pero cuando surgió el concepto de la estética de lo feo, el impacto fue evidente y se preguntaban ¿acaso existe esa estética?

Rosenkranz (1853), realizó un estudio sobre lo bello, donde partimos de la premisa que lo feo, como derivado secundario, es dependiente en su concepto de lo bello. Convirtiendo lo sublime en lo vulgar, lo agradable en lo repugnante y lo 
bello absoluto se convierte en caricatura. "Es un contrasentido, como si el enfermo o la maldad suscitaran placer” (Rozenkranz, 1853).

La comprensión de las imágenes por medio de este taller, genera en ellos un impacto visual, que los hizo comprender que no todo arte representa la naturaleza. Se puede transgredir las formas a través de muchas estéticas, que según Rosenkranz (1853), están divididas entre lo vulgar y este a su vez en lo mezquino, lo débil y lo vil, y este a su vez en lo banal, lo burdo, lo casual y arbitrario. Otro grupo es lo repugnante y aquí hallamos lo tosco, lo muerto y lo vacío, lo horrible, que lo divide en lo insensato, lo nauseabundo y lo malo, que está determinado por lo criminal, lo espectral y lo diabólico.

Ante todos estos términos y ejemplos de cada uno de ellos, concluyen que entonces la mayoría de cosas que nos rodean están enmarcadas dentro de la estética de la fealdad. Pero que aún a pesar de ello esas representaciones como lo banal donde encontraron algo de poético en las obras es una expresión fascinante de arte subjetivo y sólo así han logrado comprender muchas obras que por su significado gráfico no les inspiraba ninguna interpretación ni gusto.

En esta fase de la investigación, los resultados son lo más satisfactorios, ya que les permite a ellos reflejar resultados por fuera de la estética tradicional de la imagen, de la narración por medio de ellas, fotografía, pintura, collage, dibujo, son las técnicas exploradas. Los resultados saltan a la vista, pero más allá de esto, es el complemento teórico que justifica cada imagen representada por ellos de acuerdo a sus conocimientos y los textos en movimiento que las acompañan. La diversidad de formas, de interpretaciones devela el potencial que como maestros nos estamos enfrentando en el aula.

La falta de énfasis artístico en los programas académicos es evidente y se vuelve imperativa la necesidad de incorporar en los currículos este tipo de contenidos. Conseguir que nuestros profesionales desarrollen capacidades de raciocinio y lógica, no siempre supera en conocimiento a la capacidad sensible y de interpretación de un artista, el complemento es vital. La educación artística se debe concebir como un aprendizaje significativo, como algo que aliente la construcción del saber, la participación y la investigación.

\section{DISCUSIÓN Y CONCLUSIÓN}

En Colombia a pesar de los cambios en la ejecución de competencias desde el nivel preescolar, no promueven el énfasis en las áreas de arte o educación artística en la plástica. La educación artística debe ser vista como un área que desarrolla disciplina, actitudes, hábitos y comportamientos. Hoy por hoy no existen los medios ni las herramientas suficientes para implementar en cada programa el énfasis artístico, y esto dado por el hecho de que por décadas la importancia del desarrollo apreciativo sobre el valor de una obra artística ha sido exclusivo. Es decir, que son pocos los que realmente se forman para esto. La actividad artística debe trascender a todas las asignaturas ya que es claro que la expresión gráfica habla aún más que la expresión verbal (Arnheim, 1993)

La capacidad creativa en las escuelas, colegios y universidades ha sido un privilegio que pocos han logrado alcanzar, estadísticamente un $27 \%$ de los bachilleres escogen una carrera como Bellas Artes o Artes Plásticas. Muchas veces llevados por sus padres los lleva a estudiar carreras de mayor producción y con la posibilidad de ofrecer más estabilidad (según ellos).

Ahora, en el campo profesional de todas las disciplinas no se avala este tipo de oferta académica dentro del pensum de cada programa. Con los estudiantes estudiados se observa que sólo en Medicina, ven materias como Dibujo, pero esto dirigido hacía el conocimiento de la anatomía, obviamente existe un taller práctico del mismo. El arte justifica la interpretación del mundo, subjetiva y objetivamente, dando a los profesionales de diferentes disciplinas la capacidad alcanzable de lograr desarrollar proyectos competitivos en todo orden. Sobre los ejercicios e instrumentos piloteados los estudiantes analizaron que por medio de la estética de la imagen (como complemento de sus carreras) pueden alcanzar 
metas profesionales de gran importancia. Con cada ejercicio dieron a conocer mecanismos de implementación de la estética a cualquiera de sus proyectos académicos. Lograron formas abstractas del color, formando composiciones agradables en su movimiento, en su espacialidad. Ejercicios fuera de la naturaleza de su formación con los que llegaron a fortalecer destrezas y aptitudes que desconocían. Trabajos de alto nivel estético y artístico.

\section{REFERENCIAS BIBLIOGRÁFICAS}

Ancizar, R., \& Quintero, J. (2010). Investigación pedagógica y formación del profesorado. pdf

Arnheim, R. (1993). Consideraciones sobre la educación artística. Barcelona. ISBN: 84-7509-877-0

Carr, W., \& Kemmis, S. (1988). Teoría Crítica de la enseñanza. Barcelona-España

Demmer, F. (2013). Agencia de noticias Universidad Nacional. Recuperado de http://www.agenciadenoticias.unal.edu.co/ndetalle/article/ educacion-en-artes-acceso-minimo-para-la-poblacion-colombiana.html

Hernández, F. (2000). Educación y cultura visual. Barcelona.

Gardner, H. (1994). Educación artística y desarrollo humano. Barcelona : Paidós Ibérica.

Kandinsky, W. (1917). De lo espiritual en el arte. México D.F: Premia editora S.A.

Mediero, A., Fresno, M., Garcia, A., (2003). Las investigadoras científicas (Análisis sociológico del campo científico desde la perspectiva de género). Revista Complutense de Educación. Vol. 14 Núm. 2. ISSN: 1130-2496.

Ministerio de Cultura. (2013). Formación Artística. Recuperado de: http//www.mincultura.gov.co/ áreas/artes/educación-artistica/Paginas/default. aspx.

Ministerio de Educación Nacional (2012). Serie lineamientos curriculares. Educación Artística. Recuperado de: http://www.eduteka.org/pdfdir/ MENLineamientosArtistica.pdf

Organización para las Naciones Unidas en educación. Unesco. (2002). La sociedad del conocimiento. Revista Social de Ciencias Sociales. Número 171. Recuperado de :http://www.unesco.org/

Pérez, E. (2013). Agencia de noticias Universidad Nacional. Recuperado de http://www.agenciadenoticias.unal.edu.co/ndetalle/article/ educacion-en-artes-acceso-minimo-para-la-poblacion-colombiana.html

Pérez, S. (1994). Método de Investigación Cualitativo.

Rosenkranz, K. (1853). Revista de Letras. (9 de julio 2009). Recuperado de http://revistadeletras.net/ la-estetica-de-lo-feo/

Sundín, M. (2003) Investigación cualitativa en educación. Madrid. Capítulo 7

Sánchez, F. (2014). Félix Sánchez. Recuperado de http://www.visualwarriors.com/

Vásquez, W. (2013). Agencia de noticias Universidad Nacional. Recuperado http://www.agenciadenoticias.unal.edu.co/ndetalle/article/ educacion-en-artes-acceso-minimo-para-la-poblacion-colombiana.html 